\title{
Espacios legibles: la traducción en los márgenes del canon
}

Alicia Schniebs

Roxana Nenadic

Martín Pozzi ${ }^{1}$

Universidad de Buenos Aires

\section{Resumen}

En este trabajo presentamos la tarea de traducción de los poemas latinos Copa y Moretum al español, y mostramos las dificultades y problemáticas con las que nos enfrentamos. Enmarcamos nuestra labor en la idea de que es imprescindible desarrollar traducciones al español de obras no canónicas como una forma de ampliar y actualizar los estudios literarios.

\section{Palabras clave}

Traducción - canon - poesía latina - recursos pedagógicos

\begin{abstract}
${ }^{1}$ Alicia Schniebs es Doctora en Letras Clásicas (UBA). Profesora Titular de Lengua y Cultura Latina I-V y Directora del Instituto de Filología Clásica (Facultad de Filosofía y Letras, UBA). Ha dirigido y dirige proyectos de investigación financiados, doctorandos y becarios de posgrado. Ha participado en encuentros académicos nacionales e internacionales y ha publicado libros, capítulos y artículos sobre la especialidad en el país y en el extranjero.

Roxana Nenadic es Licenciada en Letras y doctoranda (UBA). Jefa de Trabajos Prácticos de Lengua y Cultura Latina I-V de la Facultad de Filosofía y Letras (UBA), donde se desempeña como investigadora en proyectos de investigación financiados. Ha participado en encuentros académicos nacionales e internacionales y ha publicado libros, capítulos y artículos sobre la especialidad en el país y en el extranjero.

Martín Pozzi es Licenciado en Letras (UBA). Jefe de Trabajos Prácticos de Lengua y Cultura Latina I-V de la Facultad de Filosofía y Letras (UBA), donde se desempeña como investigador en proyectos de investigación financiados. Ha participado en encuentros académicos nacionales e internacionales y hapublicado libros, capítulos de libros y artículos sobre la especialidad en el país y en el extranjero.
\end{abstract}


In this paper we present our translation into Spanish of the Latin poems Copa and Moretum, and show the difficulties and problems we came upon. We frame our work on the idea that it is essential to develop translations into Spanish of non-canonical works as a way of expanding and updating literary studies.

\section{Keywords}

Translation - canon - Latin poetry - pedagogical resources

I

Qué leer, cómo y para qué. Tres preguntas que, formuladas o no, se cuelan en las elecciones más o menos conscientes que sostienen todo acto de lectura. En nuestro trabajo, como en el de tantos otros equipos de docentes-investigadores, estas elecciones se enmarcan en un panorama delineado por diversos factores.

En primer lugar, las posibilidades que nos brinda nuestro medio académico: gracias a los avances en las comunicaciones, el creciente desarrollo del acceso abierto y la mayor conciencia en la difusión de las investigaciones para un público no experto, también se han ensanchado el rango y la cantidad de textos y materiales críticos disponibles en los centros de investigación, situación impensable apenas quince años atrás. Sin lugar a dudas, esto ha permitido no solo una actualización periódica de los contenidos sino también de los textos, pudiendo contar entonces con buenas ediciones o comentarios de obras casi desconocidas o inexistentes en nuestros espacios de trabajo. Así, con el afianzamiento y el recurso consistente a estas nuevas posibilidades, no hay excusas para no ampliar la selección de los textos que se analizan, enseñan y, en lo que respecta a este artículo, se traducen.

Con todo, y más allá de esta ampliación virtual de contenidos, no podemos dejar de lado las necesidades y obligaciones que supone la pertenencia a un espacio institucional de enseñanza como la universidad. Esto nos lleva a plantearnos infinidad de veces qué textos se deben leer y desde qué abordaje(s) hacerlo. Aquí entran de lleno las eternas discusiones en torno de la literatura canónica, la «importancia» de ciertos textos frente a otros, las consabidas «proyecciones» de la literatura clásica en textos posteriores, etc. No es una decisión fácil ni exenta de problemas, pues en definitiva todo texto tiene algo 
importante para decir, aunque no siempre sea edificante para una tradición convencional y esencialmente conservadora.

Para equilibrar estos dos factores en apariencia opuestos, nuestras convicciones y creencias nos llevaron, casi sin darnos cuenta, a modificar el proceso de construcción de nuestro corpus de lecturas, problematizando las inclusiones y las prioridades dentro de un sistema de por sí incompleto e incierto. Tenemos en claro que hay autores ineludibles e indispensables para todo aquel que se inicie en la literatura latina, pero también estamos convencidos de que hay una miríada de textos, menos conocidos y de un nivel inferior en apariencia, que tiene mucho para aportar a nuestro conocimiento del campo cultural y de la producción literaria en Roma. Cuando existe tanto al alcance de la mano, creemos, se abre una puerta para ampliar, renovar y, por qué no, cuestionar, lo que se tiene por sabido. De allí que, sin descuidar el estudio y el análisis de los autores consagrados, canónicos $\mathrm{y}$, como antes dijimos, ineludibles para todo estudiante, iniciamos sendos proyectos de investigación dedicados al estudio de dos obras extracanónicas, los Facta et dicta memorabilia de Valerio Máximo (una colección de exempla escrita bajo el gobierno de Tiberio) y la Appendix Vergiliana, antología en la que nos centraremos en estas páginas ${ }^{2}$.

A nivel teórico, a partir de ellos concluimos que las renovadas discusiones acerca del canon $^{3}$ evidencian no solo que es imposible pensar en una conformación definitiva del mismo sino también hasta qué punto su coherencia y completitud son efectos de sentido $^{4}$. Nuestras elecciones, entonces, por mejores motivaciones que tengan, son también, inevitablemente, arbitrarias e incompletas. Por ello, pensamos que un buen modo de abordar estas obras que habíamos escogido era desarticular las jerarquías intracanónicas y anular la aplicación de juicios estéticos y de valor: no son mejores los textos canónicos por bellos y famosos ni lo son los extracanónicos por olvidados. Optamos por estudiar cada texto en pie de igualdad con el resto de los integrantes del campo literario en Roma, intentando obtener una visión más dinámica. Este abordaje, descentralizado, por así decirlo, nos permitió descubrir la complejidad de obras

\footnotetext{
${ }^{2}$ Proyectos "Discurso, memoria y saber en Valerio Máximo" (UBACYT 20020100100065, 2011-2014) y "El campo literario en Roma: el caso de la Appendix Vergiliana" (PICT 2008-1900, 2010-2014), ambos dirigidos por la Dra. Alicia Schniebs y radicados en el Instituto de Filología Clásica (UBA).

${ }^{3}$ Un excelente resumen del estado de la cuestión en Anderson y Zanetti (2000:341-346).

${ }^{4}$ En este punto seguimos las distinciones de Fowler (1979:98-99).
} 
impensadas, su diálogo con los demás elementos de la serie cultural y los elementos de juicio que aportan en el estudio de distintas problemáticas que habían suscitado el interés del grupo, como la intertextualidad, las combinaciones genéricas, la representación de los agentes sociales y de las relaciones de poder, entre otros.

En el caso particular de la Copa y del Moretum (los poemas que tradujimos de la Appendix Vergiliana) descubrimos, además, que había muy pocas traducciones. Las mismas resultaban obsoletas o extrañas a nuestro medio rioplatense, sobre todo teniendo en cuenta, como veremos más adelante, las complejidades léxicas de ambos poemas. Este descubrimiento se convirtió en un desafío, y así emprendimos la tarea de preparar una traducción adecuada a nuestro medio con la correspondiente introducción y comentario para facilitar la comprensión de textos de por sí descontextualizados y complejos. Tomamos esta tarea como una oportunidad para hacer visibles estas obras menores y para resaltar su estatus dentro de la literatura latina. A su vez, la marginalidad de los protagonistas de ambas obras nos pareció un elemento capaz de enriquecer y problematizar en el lector la concepción de una antigüedad idealizada y cristalizada en ciertos motivos e imágenes bastante convencionales.

Ciertamente, los datos básicos de la Appendix Vergiliana ilustran cuán atrayente resulta en el marco de las cuestiones que hemos planteado. Recordemos que se trata de una antología de poemas de metro y género diverso, vinculados por la tradición con la juventud de Virgilio y de autoría dudosa, cuando no considerada anónima. Su fecha de composición oscila entre los primeros años del mantuano y el siglo II d.C. Suele, en general, discutirse sobre el listado de composiciones que la integran, pues los diferentes códices no incluyen los mismos textos. Estamos, pues, frente a una obra estudiada mayormente con intereses y criterios provenientes de la ecdótica y prácticamente ignorada como exponente literario respecto del canon y del resto de la producción virgiliana. Su posible anonimato y su pertenencia a una antología contribuyen a este desinterés pues es una tendencia bastante arraigada en la crítica el tomar como punto de partida para sus análisis sus ideas previas acerca de un autor. A su vez, con frecuencia las compilaciones se consideran meros ejercicios de práctica que, como tales, reiteran o parafrasean de manera irrelevante textos canónicos. En este panorama, si bien nuestro objetivo era claro (examinar la Appendix en su calidad de emergente del campo literario latino), esta suerte de lectura en los márgenes nos exigió, en cierta medida, desandar el 
tic de nuestra formación que consiste en focalizar las explicaciones de un texto a la luz de lo observado en otro. ${ }^{5}$

Por otro lado, y como ya hemos señalado, las obras que escogimos presentan un grado extra de marginalidad. En la Copa, en treinta y ocho versos de dísticos elegíacos, leemos en boca de una vieja tabernera extranjera al costado de un camino rural una invitación para que el humilde caminante descanse, beba y se entregue al placer erótico. El Moretum, en sus ciento veintidós hexámetros, desarrolla las operaciones manuales realizadas al alba por un menesteroso campesino en su choza junto con su esclava negra para obtener su único alimento: una hogaza de pan y la pasta de queso y ajo que da nombre al poema. Es decir, los textos trabajan escenas sumamente alejadas de los estándares genéricos establecidos para la poesía elegíaca y hexamétrica. Más aún, ambos se desarrollan mediante la construcción de espacios, habitantes y prácticas tan difíciles de reconstruir como de interpretar en su estilización poética. En este aspecto, nuestras indagaciones pusieron en relieve la erudición y experticia del poeta a la hora de trazar las alusiones intertextuales necesarias para ubicar a sus textos en diálogo con el sistema literario latino y de formular sus propias y exclusivas versiones de situaciones que contravienen el horizonte de expectativas del lector. Asimismo, a esta pericia que observamos se sumó otro rasgo que une estos exponentes extracanónicos con sus «hermanos mayores»: su inocultable mirada romanocéntrica, elitista y masculina.

Estos fundamentos y reflexiones nos ayudaron a dar forma a nuestra tarea de traducción que fue más ardua y problemática de lo que habíamos previsto. Sin lugar a dudas, el apartarnos de muchos automatismos del trabajo con textos en otro idioma y más aún antiguo (donde, de un modo u otro, siempre estamos traduciendo de forma «casera» e instrumental para intentar transmitir contenidos de otra índole que no siempre son tan diáfanos ni tan correspondientes en otra cultura), nos obligó a sopesar una y otra vez nuestras elecciones, discutir múltiples alternativas e investigar aspectos que no eran visibles en superficie. El resultado de este enriquecedor proceso se plasmó en dos publicaciones: Copa / La tabernera (2014) y Moretum: poema pseudovirgiliano

\footnotetext{
${ }^{5}$ Aquí son útiles las reflexiones de Martín Puente (2012) sobre la compleja relación entre la labor filológica y la atribución autoral.
} 
$(2016)^{6}$. A continuación ofrecemos algunas reflexiones sobre los problemas que afrontamos y cómo intentamos resolverlos.

\section{II}

\section{Individual / grupal}

Uno de los pilares de nuestra tarea de traducción fue, sin duda alguna, desarrollar la labor en forma grupal. A lo largo de los años nos sentimos convocados por temas, ejes y marcos teóricos compartidos y desarrollamos nuestras investigaciones dando lugar para que cada miembro del equipo se dedicara al área de su interés. Esto, por un lado, nos formó como críticos metodológicamente afines y, por el otro, nos especializó de manera complementaria. Nos pareció que la manera más lógica de sacar provecho de esta pericia adquirida a nivel individual y grupal era traducir como equipo. La calidad de los textos lo requería, dado que, según explicamos, producían una especie de «vacío contextual», ya fuera por su propia historia o por el modo en que habíamos elegido estudiarlos. Concretamente, optamos por discutir en reuniones periódicas nuestras traducciones individuales para acordar una versión del equipo que diera cuenta de los diversos aspectos que habíamos observado como lectores expertos. Una de las cosas más curiosas que notamos en este proceso fue el grado de injerencia que tenían en nuestras preferencias particulares nuestras propias evaluaciones, dificultades $\mathrm{y}$ experiencias como lectores de traducciones. Esta memoria de lectura, junto con el resto de nuestras competencias, nos permitió adoptar criterios lingüísticos, literarios y también editoriales en lo relativo a la organización y presentación del material.

El trabajo en equipo más allá de funcionar como una especie de contralor de nuestras elecciones y de la propia comprensión de los contenidos posibilitó una manera de trabajar mucho más precisa y enriquecedora - tan solo imaginar que podíamos estar

\footnotetext{
${ }^{6}$ Pseudo-Virgilio (2014) Copa / La tabernera: poema pseudovirgiliano. Edición bilingüe con estudio preliminar y comentario por A. Schniebs, R. Nenadic, J. Palacios, M. Pozzi, V. Diez y G. Daujotas. Buenos Aires: Editorial de la Facultad de Filosofía y Letras. (Disponible en acceso abierto en: http://ifc.institutos.filo.uba.ar/sites/ifc.institutos.filo.uba.ar/files/Copa\%20-\%20La\%20tabernera.pdf) y Pseudo-Virgilio (2016) Moretum: poema pseudovirgiliano. Edición bilingüe con estudio preliminar y comentario por Al. Schniebs, R. Nenadic, J. Palacios, M. Pozzi, V. Diez, G. Daujotas. Ciudad Autónoma de Buenos Aires: Editorial de la Facultad de Filosofía y Letras Universidad de Buenos Aires (disponible en acceso abierto en: http://ifc.institutos.filo.uba.ar/sites/ifc.institutos.filo.uba.ar/files/Moretum\%20poema\%20pseudovirgiliano .pdf).
} 
horas discutiendo una sola palabra o la interpretación de un verso problemático. Es preciso tener en cuenta que los textos antiguos tienen problemas de transmisión, por lo que un trabajo sólido comienza con el estudio de las variantes textuales, correcciones y enmiendas sumadas a lo largo de su azaroso recorrido. Estas suelen estar explicadas o justificadas en bibliografía especializada que debimos leer y ponderar para llegar a una solución. Muchas veces, parte de estos problemas se ven complejizados por exhibir características lingüísticas, gramaticales o sintácticas poco habituales, que también hubo que estudiar y analizar. Cuando no dimos con una explicación que nos satisficiera, y amparados en las ediciones más actualizadas, optamos por dejar la variante transmitida por los códices y mantener la indicación convencional de esta situación (las cruces): mantuvimos esta decisión también en la traducción cuando no era posible llegar a un resultado sensato. Mismo procedimiento seguimos con las lagunas.

reserat clausae +qua pervidet+ ostia claui (Moretum, v.15)

y abre las puertas ...

Otro tanto sucede con aspectos poco frecuentados del mundo clásico tales como la características de las tabernas, las comidas y los alimentos, ciertos enseres domésticos, y múltiples elementos que requirieron extensos rastreos bibliográficos y debates internos aún más extensos, ya que muchas veces las explicaciones de los especialistas contradecían tanto el sentido común como lo formulado por los propios poemas.

Indudablemente todos estos procesos también pueden ser llevados a cabo por una única persona, pero no sólo la tarea es ingente en cuanto a lecturas que llevan a otras lecturas, largas indagaciones y búsquedas bibliográficas de materiales raros y difíciles de encontrar, sino también la propia índole de las decisiones a tomar, múltiples y encadenadas entre sí, requiere toda la eficacia de un grupo consolidado para disminuir el margen de error.

\section{Legibilidad}


Muchas de nuestras decisiones se basan en el intento de conservar la legibilidad de los textos, en más de un sentido. En principio, ofrecimos una versión bilingüe, que presentaba los textos en páginas enfrentadas, manteniendo la estructura en verso para respetar aunque fuera gráficamente el esquema del texto latino, para facilitar la consulta del lector experto y para incitar la curiosidad del lector interesado, que podía tener cierta ayuda para poder seguir ambas lenguas.

Nuestra búsqueda se concentró en la combinación de lo accesible y lo adecuado al tipo textual que traducíamos. Esto nos llevó a tomar decisiones impensadas, como mantener el «tú» de la segunda persona del singular que aparece en Copa. Aunque como hablantes del español rioplatense la sordidez de su ambiente y de sus personajes nos sugiriera la utilización del voseo, consideramos que el extrañamiento provocado por el contraste entre un discurso bucólico-elegíaco y unas circunstancias prácticamente miserables podían ser perfectamente aludidas por el empleo de «tú»y «vosotros»:

vamos, reposa aquí, cansado, bajo la sombra de los pámpanos

y ciñe tu cabeza pesada con una banda de rosas

mientras arrancas, hermoso, besos de la boca de una tierna joven (Copa, vv. 31-33)

Como mencionamos, estas palabras son dirigidas a un viajante muy posiblemente de baja extracción social, e intentan convencerlo de ingresar a un tugurio de mala muerte. El contraste, que quisimos mantener, está construido en torno a la saturación de semas provenientes de la elegía de asunto erótico (corona de rosas, besos, muchacha, el descanso erotizado, etc.) y del locus amoenus bucólico (sombra, vides, sueño, etc.). La desestabilización que se produce entre el hipotexto elegíaco bucólico y la realidad presentada en el poema, bien pueden reflejarse también para un hablante rioplatense mediante la apelación a formas verbales peninsulares. Nos pareció que las formas más habituales en nuestro medio le agregaban un tono informal que no estaba presente en el original. Compárese entonces, una posible versión más cercana a nuestro dialecto: 
y ceñí tu cabeza pesada con una banda de rosas

mientras arrancás, hermoso, besos de la boca de una tierna joven (Copa, vv. 31-33)

Otro principio al que adherimos fuertemente fue el respeto por la sintaxis y el orden de palabras del español, para que la traducción fuera inmediatamente comprensible. En algunos casos aislados mantuvimos la estructura de la frase o algún fenómeno lingüístico inusitado porque su rareza, sin obstaculizar el sentido, consistía en un aspecto digno de comentar, tal como la curiosa forma de las enumeraciones en la Copa:

Hay jardines y refugios, jarras, rosa, flauta, cuerdas

Sunt topia et calibae, cyathi, rosa, tibia, chordae (v. 7)

Lamentablemente hay estructuras, habituales en la poesía y que se sirven del orden libre de constituyentes que tiene el latín, que no se pueden trasladar literalmente por implicar una violencia a la inteligibilidad del texto. Así, no nos quedó más alternativa que deshacer el quiasmo

et strepitans rauco murmure riuus aquae (Copa, v. 12)

donde el sintagma «strepitans riuus» encierra a la frase «rauco murmure», pero que debimos traducir por «un arroyo que resuena con el murmullo ronco del agua». De haber mantenido el correcto aunque inusitado «un arroyo que con el murmullo ronco del agua resuena», hubiéramos mantenido la figura pero generando una especie de remedo poético afectado en nuestra lengua. Rara vez se pueden trasladar con precisión las aliteraciones, otro recurso frecuente en la poesía latina:

Vix umquam urbani comitatus merce macelli (Moretum, v. 81) 
que elegimos traducir por «raramente acompañado alguna vez de mercancía de la feria citadina», sin poder reproducir el juego fónico de las sonidos $/ \mathrm{k} / \mathrm{y} / \mathrm{m} /$.

Otro criterio que discutimos largamente fue hasta qué punto era aceptable trasladar al español ciertos ítems léxicos fundamentales, específicamente los nombres parlantes de los protagonistas y la pasta alimenticia denominada moretum en latín. En este último caso, decidimos que lo apropiado era mantener la palabra en su lengua original, pues no contamos en la actualidad con un término realmente equivalente del proceso y del resultado culinario. Por otra parte, la solución propuesta en otras versiones, almodrote, resultaba inusitada para nuestro español rioplatense. Decidimos aquí que el comentario complementara a la traducción explicando lo necesario. Algo similar ocurrió con el nombre de la tabernera, Surisca, y, en el moretum del campesino, Simulus y su criada Scybale, que significan literalmente «siria», «chatito» y «excremento». Consideramos que llamar «Siria» a la mujer implicaba una decisión extrema que daba por sentada una ortografía incomprobable para nosotros (nos referimos al empleo de la mayúscula que no se utilizaba en los manuscritos). Por el contrario, rescatar el valor del gentilicio traduciendo sencillamente «siria» nos permitía retomar en el comentario el dato étnico para incorporarlo a la serie de atributos descriptores de este sujeto marginal. En Moretum, a su vez, transliteramos Simulus -Símulo-, ya que el diminutivo «chatito», «ñatito» reducía de algún modo el sistema de connotaciones del original. Mucho más todavía en el caso de la criada «excremento», que se basa en la proximidad fónica con un término griego, y que un lector bilingüe fácilmente hubiera decodificado. Haber utilizado «la criada Excremento» hubiera dado un matiz explícito a un contenido sugerido. Siguiendo la mecánica expresada anteriormente, reservamos para el comentario la contribución del nombre a la caracterización general de los personajes.

Tal como señalamos al inicio del trabajo al mencionar nuestro extrañamiento respecto de los elementos y prácticas incluidas en estos textos, muchas veces se conjugaron la dificultad de comprender con claridad el referente de un ítem en particular y la selección de un vocablo que lo tradujera. Como ejemplo citamos el sustantivo calyba que figura en el verso 7 de Copa. Encontramos que el término designaba construcciones desmontables que solían armarse al aire libre, sobre todo en espacios verdes intervenidos por la mano del hombre, lo cual permitió aclarar el sentido del verso pero no facilitó la selección del «término perfecto» -traducir «gazebo» hubiera sido 
anacrónico. Nos decidimos por una palabra neutra como «refugio», cuya especificidad trabajamos en el comentario. Más complejo aun fue buscar un sucedáneo para un término poco atestiguado y derivado del anterior, calybita (v. 25), dado que tampoco la solución anterior era conducente: «refugiado» tiene una connotación muy diferente, si bien etimológicamente sí podía comprenderse. Optamos por utilizar la paráfrasis «huésped de estos refugios» por parecernos la forma más adecuada de conservar la vinculación con calyba sin agregar matices propios de una traducción más literal. Por el contrario, en otros casos, optamos por una versión más genérica, cuando el contexto permitía la inferencia y se podía evitar una paráfrasis innecesaria o que saturaría la versión. Tal es el caso, por ejemplo, del sustantivo carnaria en Moretum v. 55 («non illi suspensa focum carnaria iuxta») que optamos por traducir por «no tenía él ganchos suspendidos junto al brasero». Si bien estos carnaria son ganchos específicos para colgar las postas de carne, nos pareció innecesario agregar esta especificación.

\section{Los receptores}

Uno de los puntos de mayor impacto en nuestra reflexión fue el intento de determinar el receptor probable de nuestra traducción y comentario. Nuestra larga experiencia como docentes nos permite concluir que no existen casi elementos que puedan darse por conocidos. Y cada generación es distinta a la anterior en intereses, saberes e inquietudes. Los cambios curriculares también han modificado el rango de conocimientos y la heterogeneidad que hoy implica la expresión «cultura general». La vieja presunción de un «lector culto», entendiendo por este a un ser más o menos informado de los rasgos generales del mundo antiguo, los héroes homéricos, los principales autores, los rudimentos de la mitología clásica, una línea de tiempo esquemática pero suficiente como para poder ubicar ciertos hitos esenciales, ya hace tiempo que no puede sostenerse. Esto nos llevó a cuestionarnos cada afirmación y cada saber implícito presente en los textos y proveer, cuando lo consideramos necesario, notas explicativas en el comentario. Por citar algunos, los dioses mencionados en ambos poemas (Ceres, Vesta, Príapo, Vulcano, etc.), las plantas y vegetales poco conocidos, los instrumentos musicales, la vestimenta y demás aspectos contextuales del espacio y la historia de Roma. 
Pero no todas son carencias en este nuevo lector que se perfila: es un lector que demanda también otras inquietudes en los textos, que no los sacraliza y es mucho más sensible a planteos de índole teórica y literaria. En este sentido hemos destinado no solo en el estudio preliminar sino también en el comentario un espacio mayoritario a señalar y problematizar este tipo de cuestiones. Hemos sido particularmente conscientes de los problemas vinculados con los géneros discursivos, la intertextualidad, las formaciones ideológicas, las estructuras de poder y otros aspectos que han ingresado a la agenda crítica en las últimas décadas. Confiamos así en poder brindar una experiencia de lectura enriquecedora que integre la mayor cantidad de niveles de sentido posibles.

\section{III}

Como va de suyo, más allá de tener la certeza de haber trabajado a conciencia y con honestidad, no somos nosotros los indicados para aseverar que estos productos constituyen efectivamente el aporte que pretendimos ofrecer. Pero lo que sí estamos en condiciones de afirmar es el aporte que esta experiencia proveyó y provee a nuestro quehacer como docentes-investigadores. En efecto, encarar una traducción de este tipo, pensada para un público amplio que incluye a estudiantes y especialistas, pero también los trasciende, implicó una suerte de retroalimentación entre la investigación y la docencia. Esto nos llevó a un replanteo no solo de los métodos críticos y de lectura sino del modo como encaramos y renovamos los contenidos, las estrategias y la difusión de nuestra labor de estudiosos y docentes de un universo cultural sobre el que todavía queda mucho por decir y por pensar. Así, por un lado, reformulamos nuestros programas y clases del grado y del posgrado incorporando nuevos textos y nuevos paradigmas. Por el otro, dentro del ámbito de nuestra facultad pero fuera del marco curricular, formamos talleres de traducción y comentario de textos clásicos en lengua latina con vistas a capacitar a nuestros graduados en algo que la carrera no enseña. Nos gustaría que aumenten y se afiancen estas experiencias de traducción y comentario para favorecer que un público cada vez más heterogéneo y diverso se acerque a aspectos novedosos del mundo antiguo. 


\section{Bibliografía}

Anderson, E. y Zanetti, G. (2000). Comparative Semantic Approaches to the Idea of Literary Canon. The Journal of Aesthetics and Art Criticism, (58.4) 341-360. Hoboken, New Jersey: Blackwell Publishing.

Fowler, A. (1979). Genre and the Literary Canon. New Literary History, (11.1)97-119. Baltimore: The Johns Hopkins University Press.

Martín Puente, C. (2012). Tratamiento de obras anónimas y de dudosa autoría en la Filología Latina. En Martínez, J. (Coord.) Mundus vult decipi. Estudios interdisciplinarios sobre falsificación textual y literaria (pp. 213-226). Madrid: Ediciones Clásicas. 